\title{
NEW ROTOR BLADE PROFILES PERFORMANCE DECAY IN HORIZONTAL AXIS WIND TURBINES OPERATING IN AGGRESSIVE ENVIRONMENT
}

\author{
Giovanni Maria De Pratti - "La Sapienza” University of Rome - DIMA ${ }^{1}$
}

\begin{abstract}
At the present time many wind power plants have been developed in mountainous areas, in off-shore sites also at high latitudes and however operating in harsch climate or aggressive environment conditions. In these conditions HAWT's rotor blades may experiment erosion, corrosion, exfoliation and icing and these operative conditions may cause a remarkable aerodynamical performance decay resulting in a reduction in energy production due to a lower machines availability too. Traditional aerodynamic profiles, as NACA ones, can show high sensitivity to the surface damage or augmented roughness, while new airfoils as FFA-W1 series may be very useful in maintaining higher aerodynamical performance. In the present paper the aerodynamic performances of new and old airfoils have been analysed and compared on a water table test bench and wind tunnel one, at "La Sapienza" University of Rome in DIMA's laboratory, in several operative conditions, and, particularly, effects due to icing, erosion and other ones as corrosion and fouling. The results have been compared with literature data to obtain useful indications in design of new rotor blades.
\end{abstract}

\section{Introduction}

In last three decades, many wind power plants have been developed in mountainous areas, in off-shore sites also at high latitudes, as in the North Sea, and however operating in harsch climate or aggressive environment conditions.

In these different conditions HAWT's rotor blades have been experimented erosion, corrosion, exfoliation and ice accretion (icing), particularly at the leading edge (L.E.) and the typical operative conditions of above mentioned sites have caused remarkable aerodynamical performance decay resulting in a reduction in energy production due to a lower machines availability too [10].

\footnotetext{
${ }^{1}$ Corresponding Author: giovannimaria.depratti@uniroma1.it
} 
In the global park of wind turbines installed in all over the world, we have rotor blades based on NACA's series profiles and other based on SERI's, DEL's and FFA's too.

Traditional aerodynamic profiles, as NACA ones, can show high sensitivity to the surface damage or augmented roughness, while new airfoils as FFA-W1 series may be very useful in maintaining higher aerodynamical performance as shown in previous papers [4] and [4b].

The erosion and corrosion, as fouling and exfoliation at the blade L.E. produce a surface roughness increase while ice accretion, at the same L.E., modifies the surface and the upper and lower surface of the blade profiles as shown in [4c].

Particularly, also ice accretion may produce an increased roughness on airfoils surface as shown in $[4 \mathrm{c}]$.

For a long time the effects of ice accretion on aerodynamical surfaces has been a relevant item for aeroplane safety, but with the diffusion of HAWTs (Horizontal Axis Wind Turbines) in mountainous and high latitude or harsch climate sites, many very dangeorus icing damage events have been registered. The ice growth adds mechanical stress to the wind turbine rotor blades and affects aerodynamic performance as a consequence of the L.E. modification. Icing is produced when subcooled water droplets impinge on the blade surface and the shape of the ice accretion may be different as a consequence of the tempetarure and the air moisture [4c].

The blade surface roughness is a very important factor influencing the start-up of the ice formation as well as its final shape. It has long been known that surface roughness, expecially near the L.E., has large effects on the performance of wing sections, particularly, affecting the maximum lift coefficient but also the slope of lift curve and, in some cases, the zero lift angle too. Therefore it is desiderable to determine the relative effects of the L.E. roughness increase on various wing sections and the consequent performance decay during the operative running period of a blade [1].

To analyse the effects of roughness increase and of the ice accretion on L.E., after perhaps ten years in experimental search, it was very important to propose same specific shapes of L.E. modified by erosion, exfoliation, delamination, corrosion or ice accretion, and resulting in a general roughness increase, as in the following Figs. 1, 2, 3, 4, 5 and 6. The shapes shown have been detected by the Author in several wind turbines in Italian sites in mountainous areas and by mainteinance journals concerning of HAWTs in several European sites at high latitude or in harsch climate sites. 
Figure 1. Typical ice accretion shape on wings

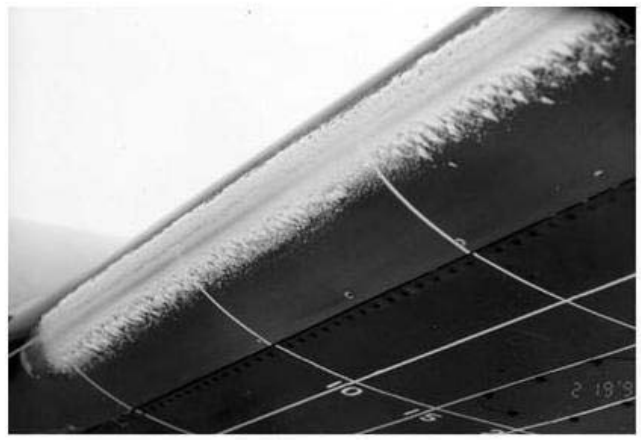

a) Rime Ice

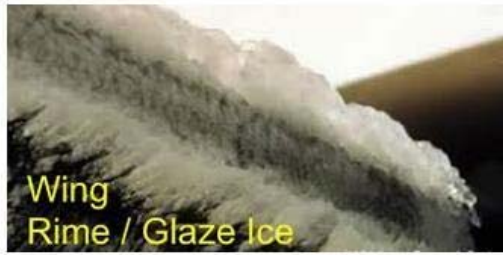

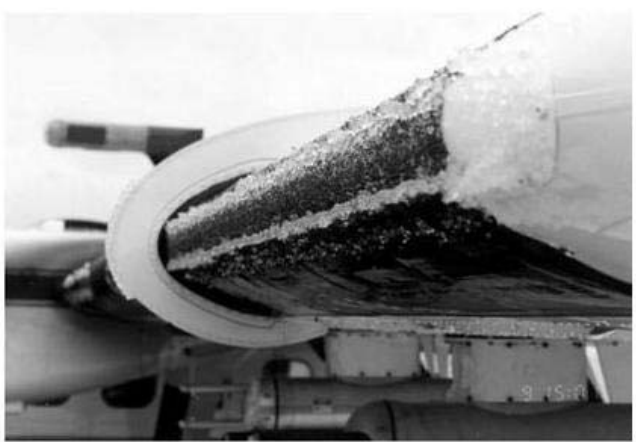

b) Glaze Ice

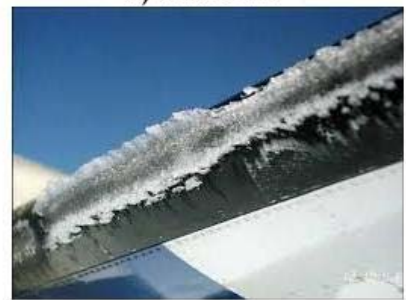

Types of ice accretion on wing and blade

Glaze ice accretion at the L.E.

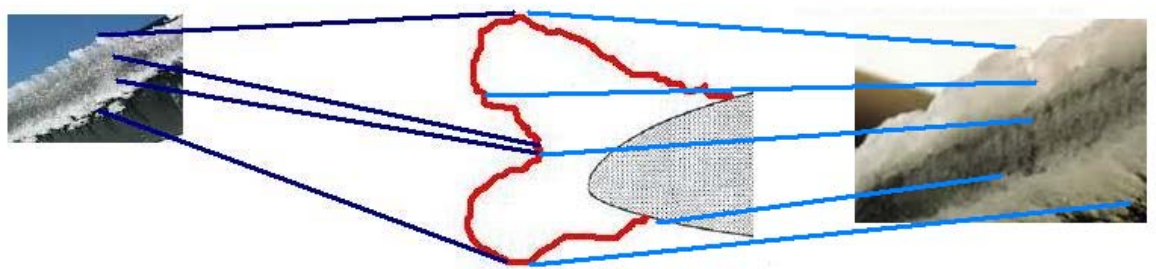

Rime ice accretion at the L.E.

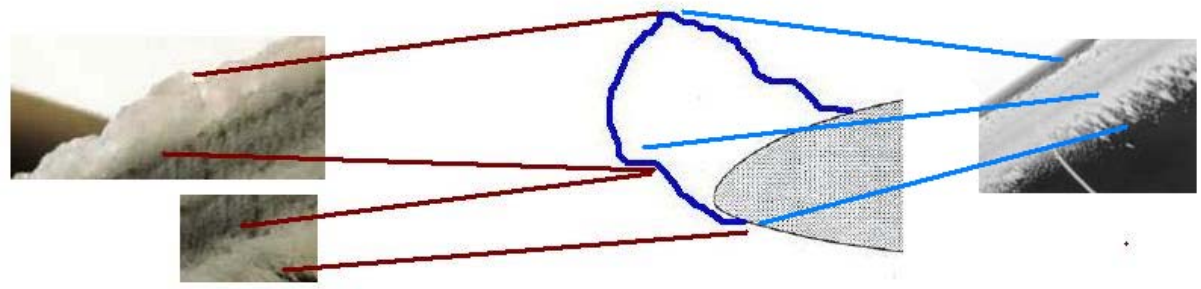

As experienced on several wind turbines rotors equipped by blade shaped with NACA conventional airfoil series, the ice shapes and the roughness increases detected have been proposed for the new profiles as shown in [4].

The analysis carried out may be very useful in designing new rotor blades.

The new airfoils taken into account were NREL S809 and FFA-W1-182 and their behavior has been compared with NACA 23018 airfoil one's. 
Figure 2. Roughness modifications at the L.E. for a NACA 23018 airfoil

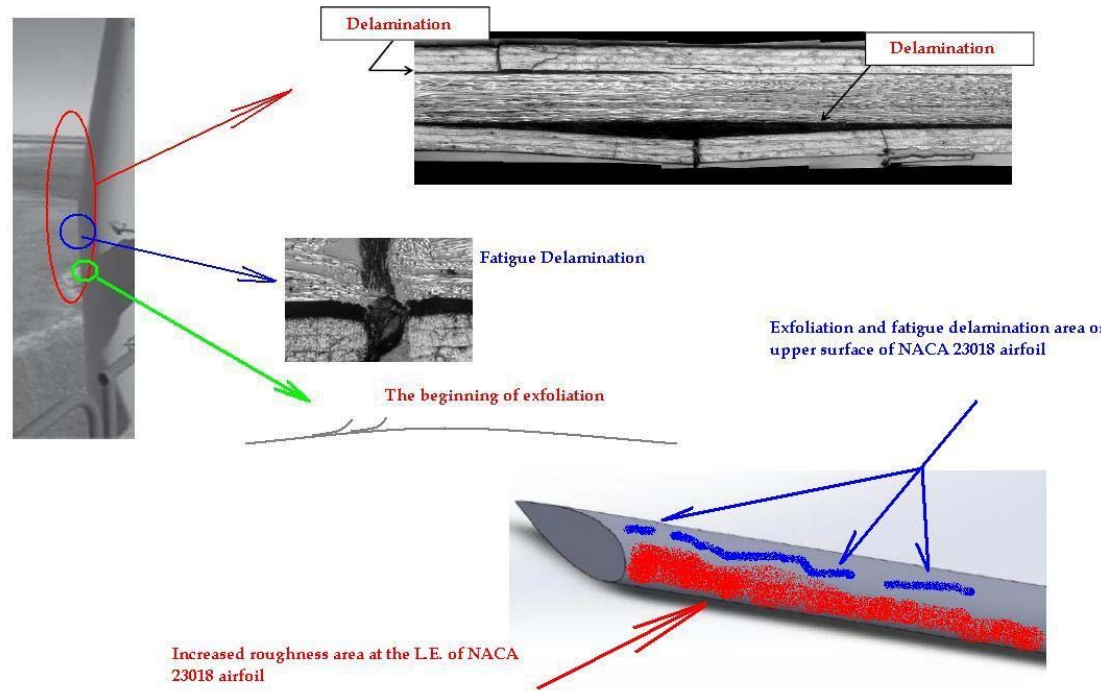

Figure 3. Roughness increase for FFA-W1-182 airfoil

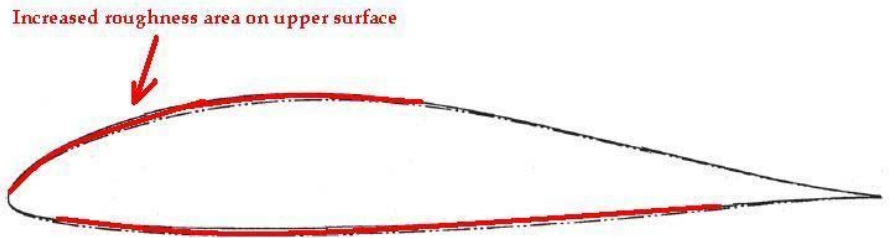

Increased roughness area on lower surface

FFA-W1-182

Blade element realised with FFA-W1-182 airfoil

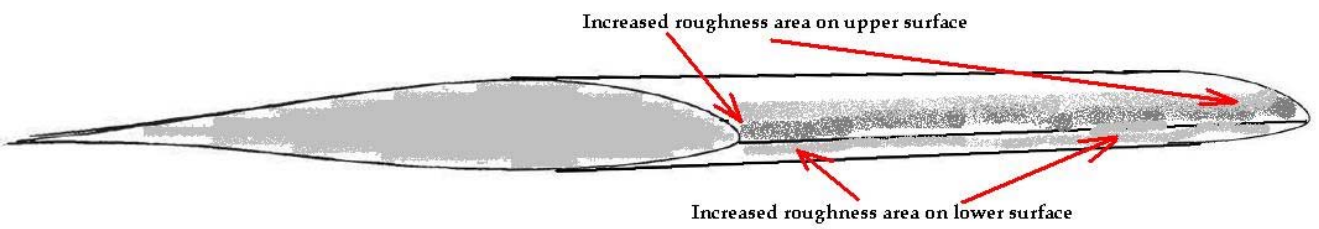

The Figs. 2 and 3 show the roughness increase taken into account for NACA 23018 (detected) and for FFA-W1-182 (proposed) and the same was done for NREL S809 in Fig. 4.

The ice accretion shapes for the old NACA 23018 and for new profiles have been shown in Figs. 4, 5 and 6 . The wing sections characteristics data have been collected from [1], [5], [6], [7], [11], [12] and [13]. 
Figure 4. Modifications at the L.E. of a NREL S809 profile

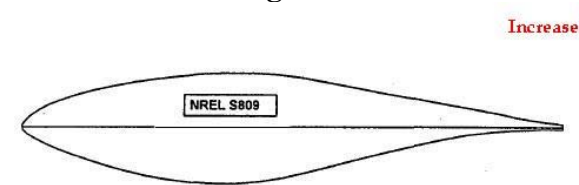

PRIMARY OUTBOARD AIRFOIL, 75\% RADIUS

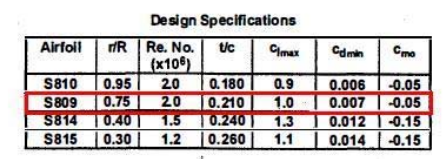

Thick-Airfoil Family for Large Blades (low tip $c_{1, \max }$ )

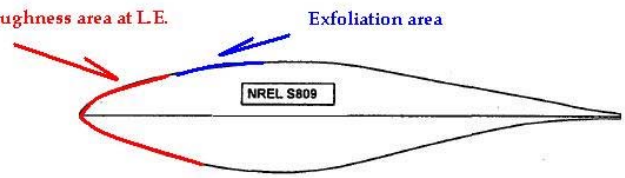

PRIMARY OUTBOARD AIRFOIL, 75\% RADIUS

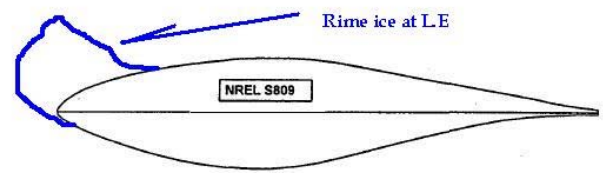

PRIMARY OUTBOARD AIRFOIL, 75\% RADIUS

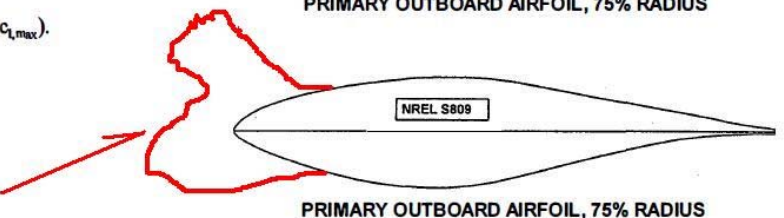

PRIMARY OUTBOARD AIRFOIL, 75\% RADIUS 
Figure 5. Ice accretion shapes for FFA-W-182 airfoil
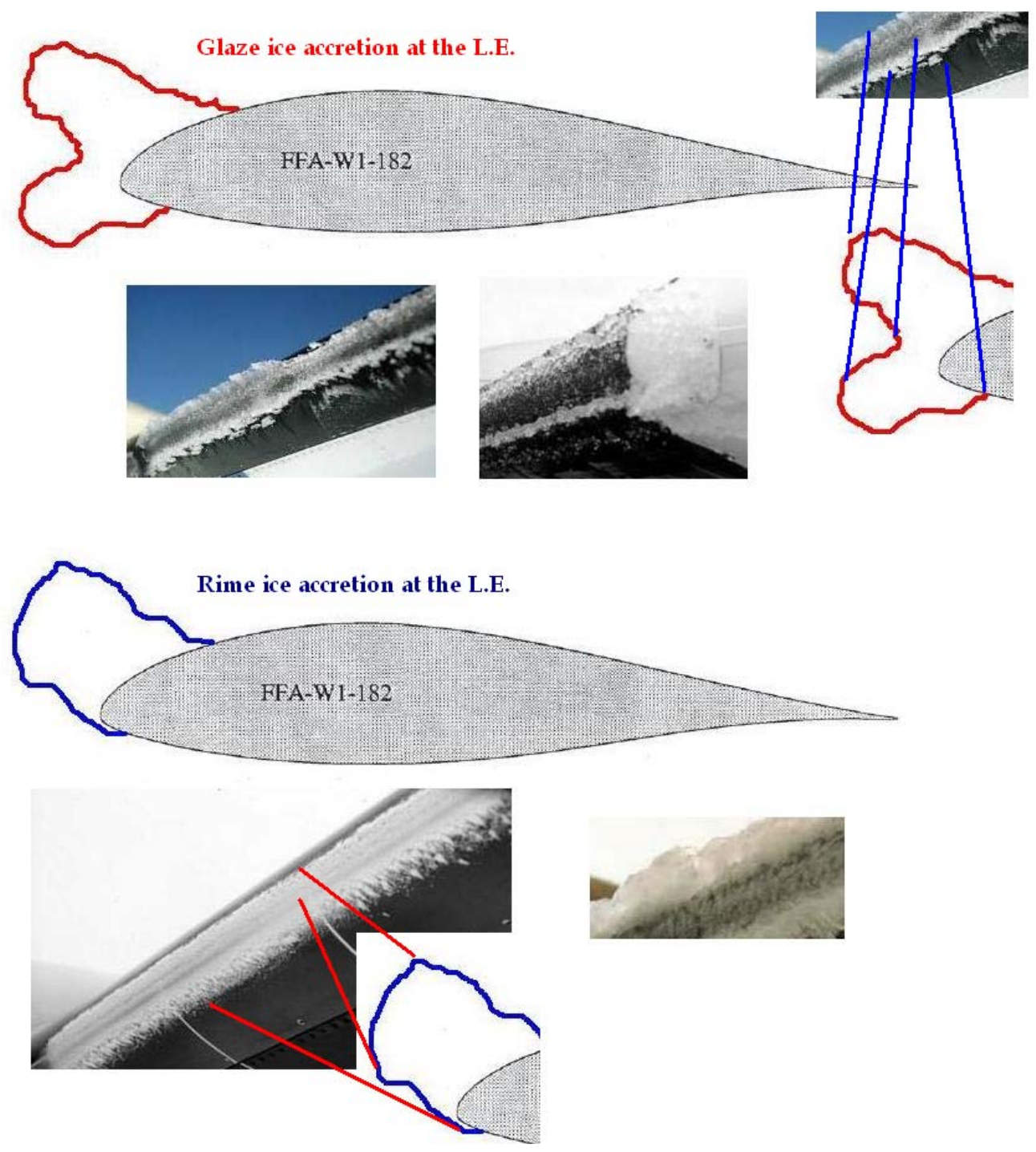
Figure 6. Ice accretion shapes at the L.E. in NACA 23018 profile

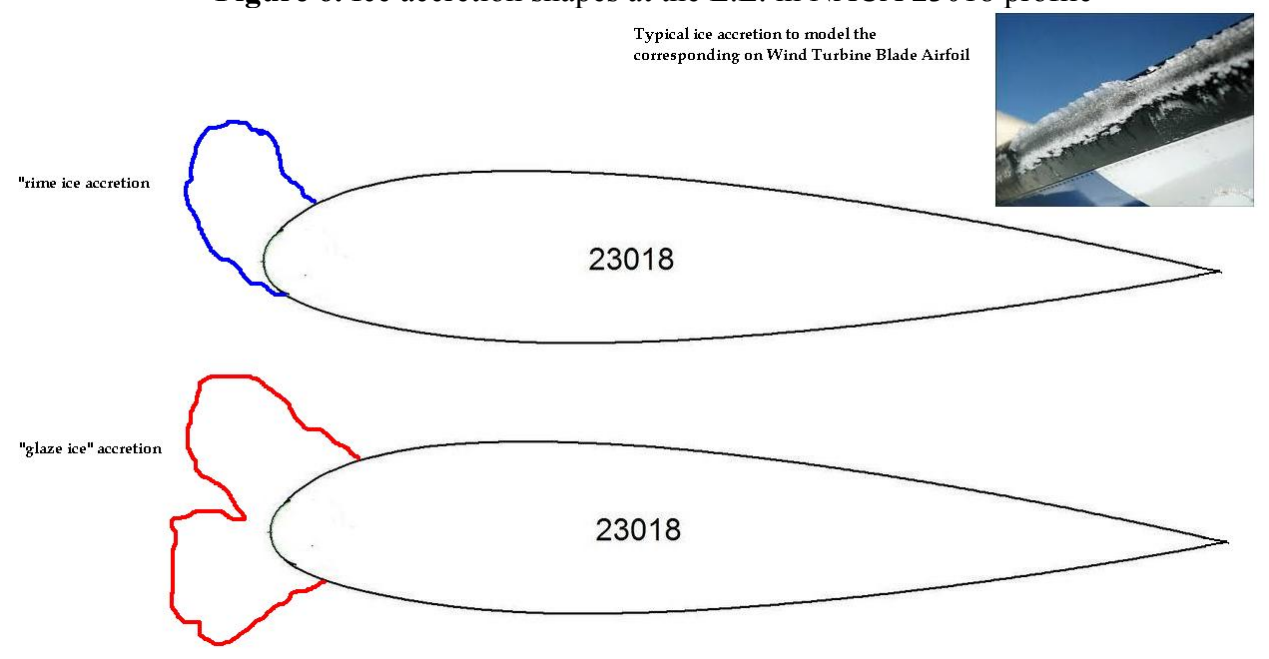

A preliminary analysis was carried out in [4], [4b] and [4c], while in the present paper the aerodynamic performances of new and old airfoils have been analysed and compared on a water table test bench and wind tunnel one, at "La Sapienza" University of Rome in DIMA's laboratory, with different operative running conditions resulting in different ice accretion shapes at the L.E. and different roughness increase values at the same location.

The results have been compared with literature data to obtain useful indications in design of new rotor blades.

\section{Airfoils data and characteristics}

As above mentioned the main data for NACA 23018 have been taken from [1], while data about one of the most promising airfoil, FFA-W1-182 have been collected by [2] and [3].

The Fig. 7 shows the original shape of FFA-W1-182 from [3] (lift coefficient $-\mathrm{C}_{1}-$ and pitching moment coefficient $-\mathrm{C}_{\mathrm{m}}-$ are shown). 
Figure 7. FFA-W1-182 original shape
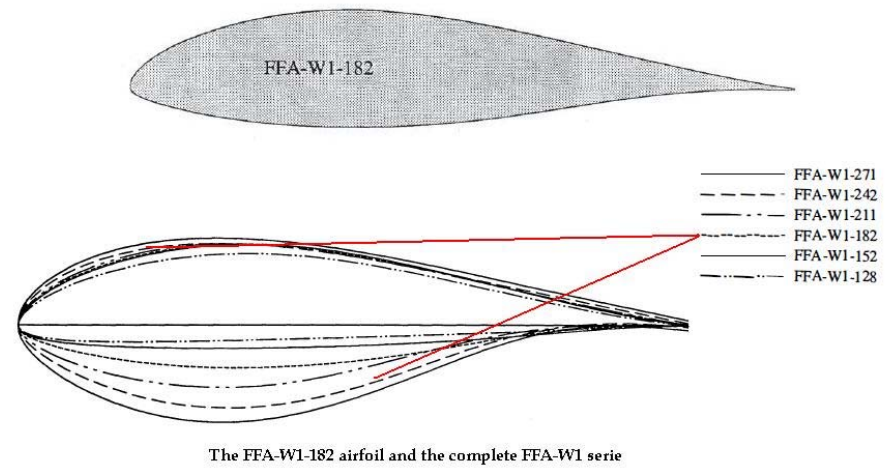

Pressure coefficient in the original shape of airfoil

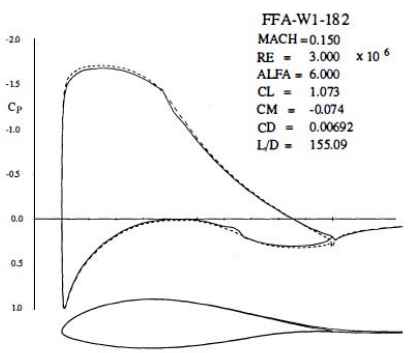

Figure 8. Lift coefficient curve of FFA-W1-182 (original shape) [3]
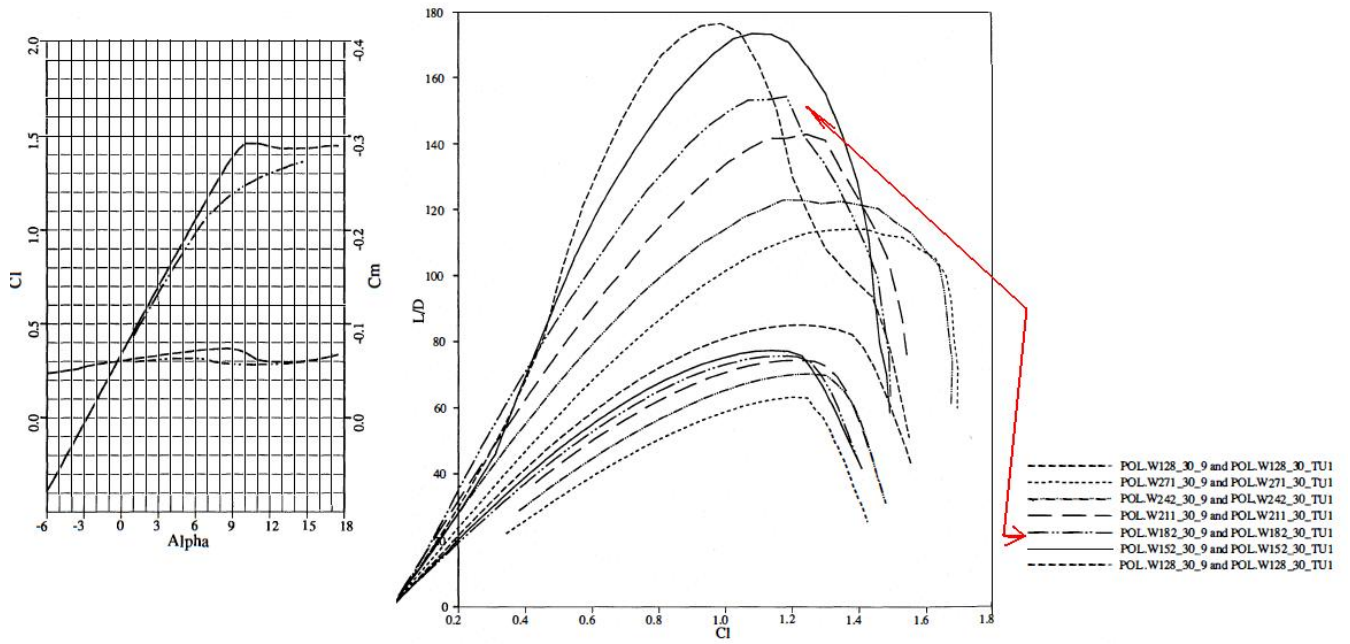

The data about NACA 23018 are shown in Fig.17 and the referring data for NREL S809 are collected in Fig. 4.

\section{Test equipment and tests carried out}

The profiles, which were reproduced in similitude and on a reduced scale, were tested using Lamb's Hydraulic Analogy on the Water Table Test Bench at the 'Dipartimento di Ingegneria Meccanica ed Aerospaziale' at the University of Rome. As known, the rules shown in Table 1 below are valid for the analogy. As known, in the Hydraulic Analogy, the Reynolds number (Re) cannot be reproduced in the same way as the Mach number, that is equal to the Froude number. However, on the basis of an important contribution by [8] it has been shown through experiments that the efflux in the air and on the Water Table behave in the same way even if the Re numbers are different. The 
tests, as established by [4], were carried out within the Re range in which the Strouhal number is kept independent from Re's variation, with the undoubted benefit of being able to take advantage of the lengthening of non-stationary phenomena made possible by the Analogy. In Lamb's Analogy, the exponent $\mathrm{k}$ of the adiabatic process is equal to 2 and not to 1.4, thus, by approximating the efflux in the air with that in the "hydraulic gas" an error is introduced which increases with the Ma number. This error is between $4.5 \%$ for $\mathrm{Ma}=\mathrm{Fr}=0.4$ and $13.3 \%$ approximately, where $\mathrm{Ma}=\mathrm{Fr}=0.5$ as shown in Fig. 9.

Specific corrections have been taken into account such that the chord, for some attack angles, becomes of the same order of magnitude as the flow free section.

Table 1. Characteristic parameters of Lamb's Analogy

\begin{tabular}{|c|c|}
\hline Gas flow & Water flow \\
\hline Pressure Wave Speed: $\mathrm{c}=(\mathrm{KRT}){ }^{\wedge} 0,5$ & Gravity Long Wave Speed: $\mathrm{a}=(\mathrm{gh}) \wedge 0,5$ \\
\hline Mach Number: $\mathrm{Ma}=\mathrm{u} / \mathrm{c}$ & Froude Number: $\mathrm{Fr}=\mathbf{l} / \mathbf{a}=\mathbf{l} /((\mathrm{gH}) / 0,5)$ \\
\hline Density ratio: $\mathbf{r} / \mathbf{r} 0$ & Water Heights Ratio: $\mathbf{h} / \mathbf{h} 0$ \\
\hline Pressure coefficiente ratio: $\mathrm{p} / \mathrm{p} 0$ & Water Heights Squared Ratio: $(\mathbf{h} / \mathbf{h} 0)^{\wedge} 2$ \\
\hline Temperature Ratio: $\mathrm{T} / \mathrm{T} 0$ & Water Heights Ratio: $\mathbf{h} / \mathbf{h} 0$ \\
\hline
\end{tabular}

Figure 9. Diagram showing the evaluation of error using the Analogy
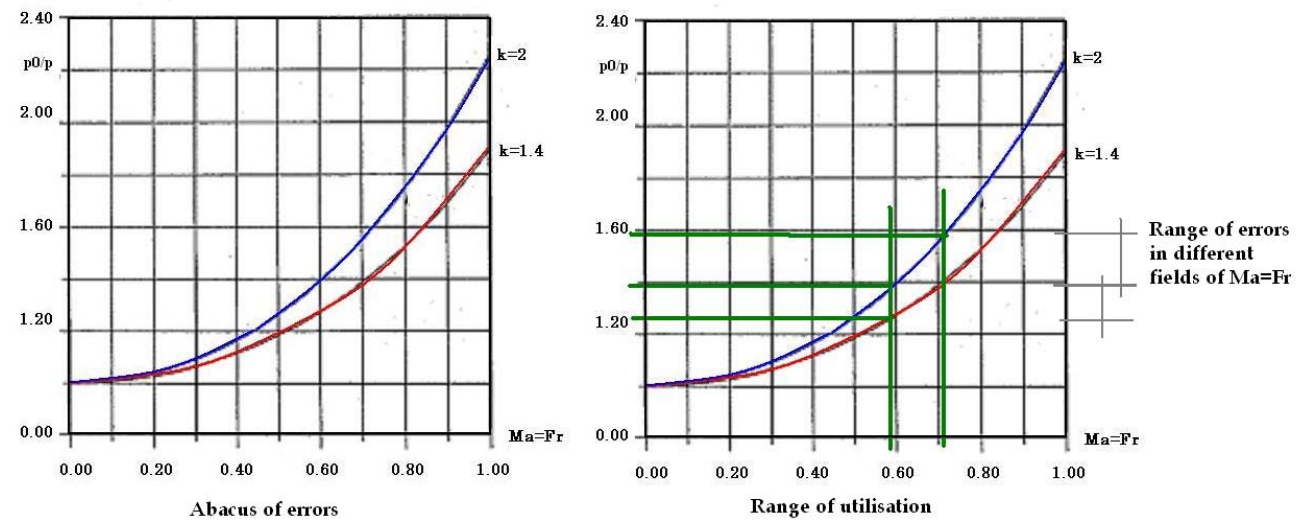

The above mentioned corrections are provided (in terms of the lift coefficient $c_{1}$ ), with reference to the chord $\mathrm{c}$ and length of the test section $\mathrm{h}$, from:

$$
\Delta c_{L}=c_{L} \cdot\left[-\frac{\pi^{2}}{48} \cdot\left(\frac{c}{h}\right)^{2}+\frac{7 \cdot \pi^{4}}{3072} \cdot\left(\frac{c}{h}\right)^{4}\right]
$$

The tests have been carried out on water table test bench and on 1-m open section wind tunnel at the same Laboratory too. The models tested on water table test bench were $70 \mathrm{~mm}$ in height and 220 $\mathrm{mm}$ in chord length, while the water height in the channel was ranging 35-50 $\mathrm{mm}$ with $\mathrm{Fr}=\mathrm{Ma}=0.4472$, realizing about $\mathrm{Re}=37,603$ (according to [8], this value corresponds in the Analogy to about 3 million on wind tunnel device). 
The wind tunnel is showed in Fig. 10, while in Fig.11 is showed the speed distribution in the wind tunnel open section.

The wings tested on the wind tunnel device were $1,000 \mathrm{~mm}$ in spanwise and $480 \mathrm{~mm}$ in chord length. To detect the pressure coefficient $\left(\mathrm{C}_{\mathrm{p}}\right)$ a multitube variable inclination high precision manometer has been used, and while for the water table $C_{1}$ is assessed by eq. (2), for the wins tunnel, the same thing may be done by eq. (3)

Figure 10. The Wind Tunnel at DIMA

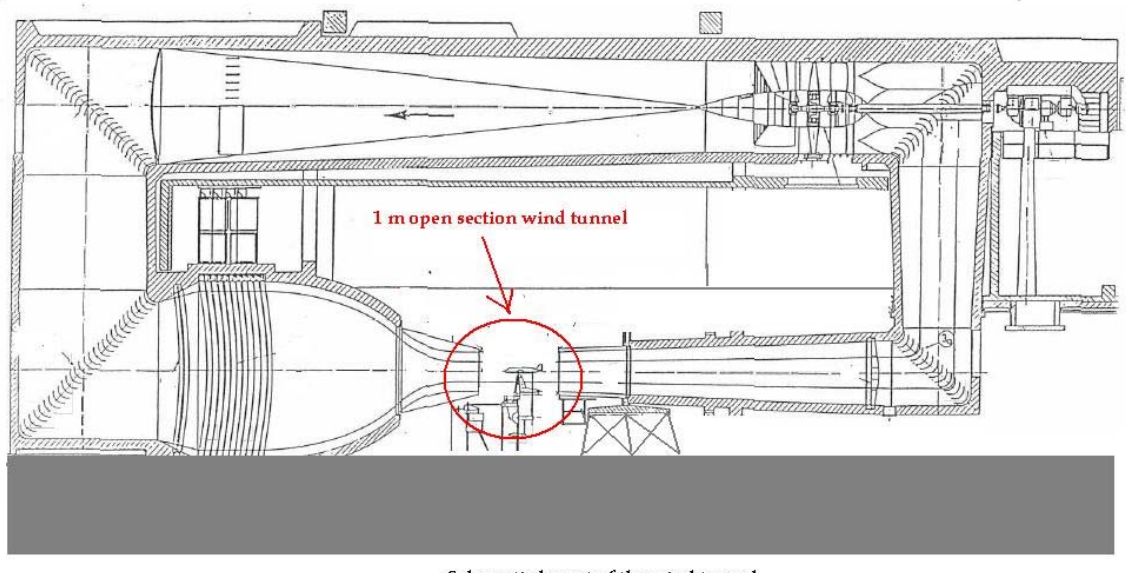

Schematic layout of the wind tunnel

Figure 11. Speed distribution in wind tunnel open section
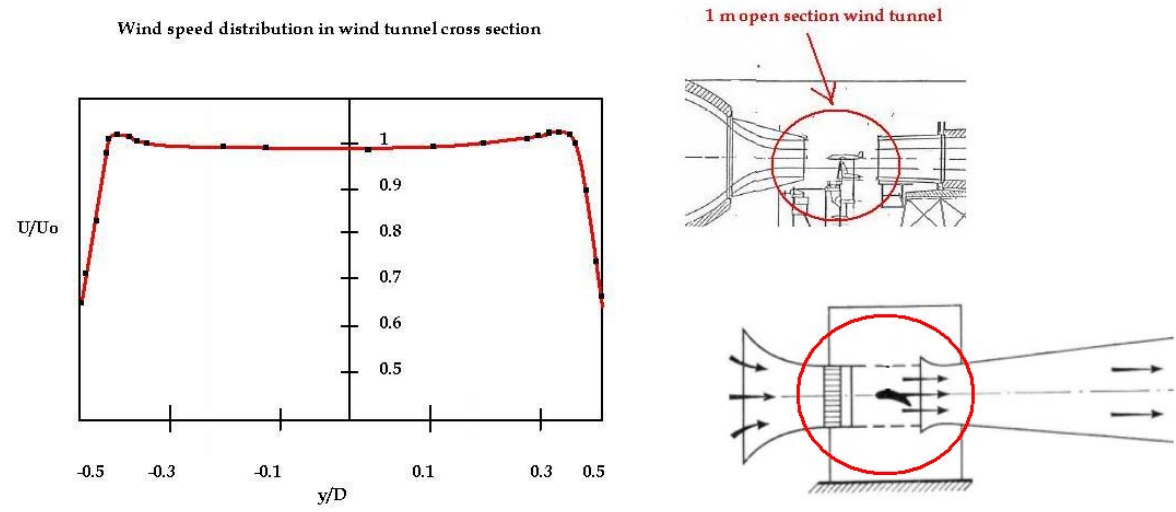

The speed measures on the wind tunnel have been carried out by a conventional pitot tube, while on the water table the pitot tube by Shapiro was used [9].

Taking into account the operative running conditions of HAWTs rotor blades, tests have been carried out with the following parameters:

A) wind tunnel: $\mathrm{Ma}=0.15$, alpha $=6^{\circ}$ and $\mathrm{Re}=3$ millions; 
B) water table test bench: $\mathrm{Fr}=\mathrm{Ma}=0.4472$, alpha ranging $-10^{\circ} / 10^{\circ}$ and $\mathrm{Re}=37,603$ (simulating 3 millions as in [8].

In every case, tests were then carried out both on profiles in the original conditions and with varied characteristics due to roughness increase and ice accretion even in similitude conditions. Test outlines are shown in Figs. 14, 15, 16, 17, 18 and 19, while the following typical equation was used to calculate the lift coefficient on the water table test bench:

$$
c_{L}=\frac{\cos \alpha}{2 \cdot F r^{2} \cdot h_{\infty}^{2} \cdot l} \cdot \sum_{i}\left[\left(h_{i}^{2}+h_{i+1}^{2}\right)_{\text {sup }}-\left(h_{i}^{2}+h_{i+1}^{2}\right)_{\text {inf }}\right] \cdot X_{i}
$$

where $\mathbf{I}$ is the chord length, $\alpha$ the angle of incidence (or attack), $\mathbf{h}$ the height at the sides of the profile and $\mathbf{X}_{\mathbf{i}}$ the points of measurement along the chord.sha

For the wind tunnel the corresponding eq. is:

$$
c_{L}=\int_{0}^{1}\left(C_{p l}-C_{p u}\right) d\left(\frac{x}{c}\right)
$$

where $\mathrm{C}_{\mathrm{pl}}$ and $\mathrm{C}_{\mathrm{pu}}$ are, respectively, the pressure coefficient on the lower and upper surface of the airfoil, " $\mathrm{x}$ " is the general station on the chord and "c" the chord length.

In the wind tunnel the pressure coefficient $(\mathrm{Cp})$ was detected together the lift one, while, generally, the lift coefficient $\left(\mathrm{C}_{\mathrm{l}}\right)$ was measured on the water table test bench in flow condition more similar to real operative running one (profiles with aspect ratio 18 are proper use at the blade height 0.75 of blade length spanwise).

The ice accretion shapes have been realised as suggested by those detected on wind turbines blades in several mountainous areas as at Frosolone and Collarmele (in Molise and Abruzzi Regions in Italy), particularly they have been verified according the main models of ice accretion about 12 $\mathrm{mm} / \mathrm{h}$ thickness addeed to the L.E. (see [4c]).

The surface increase of roughness has been obtained with sandpaper strips applied at the L.E. in wind tunnel tests, while on the water table wrinkled graph paper has been applied in the same region of the airfoil surface.

\section{RESULTS ANALYSIS}

The test results have been collected in a long period between 2001 and the end of 2019 because of the search has been carried out with lack of University funds but self-financed by the Author. In this way many results have been obtained with differente devices and software no longer available. So the following Figs. have different format. The Fig. 20 shows an abacus to solve the problem and to obtain a sake comparison clarity about $C_{p}$ while Fig. 21 the same for $C_{1}$. The Figs. 14, 15 and 16 show the results as pressure coefficient detected on wind tunnel, while Figs. show the lift coefficient detected on the water table test bench.

In the Fig. 13 the effect of roughness increase at the L.E. is shown as detected on the water table test bench and for FFA-W1-182 airfoil (Fig 12).

Figure 12. FFA-W1-182 on the water table test bench 


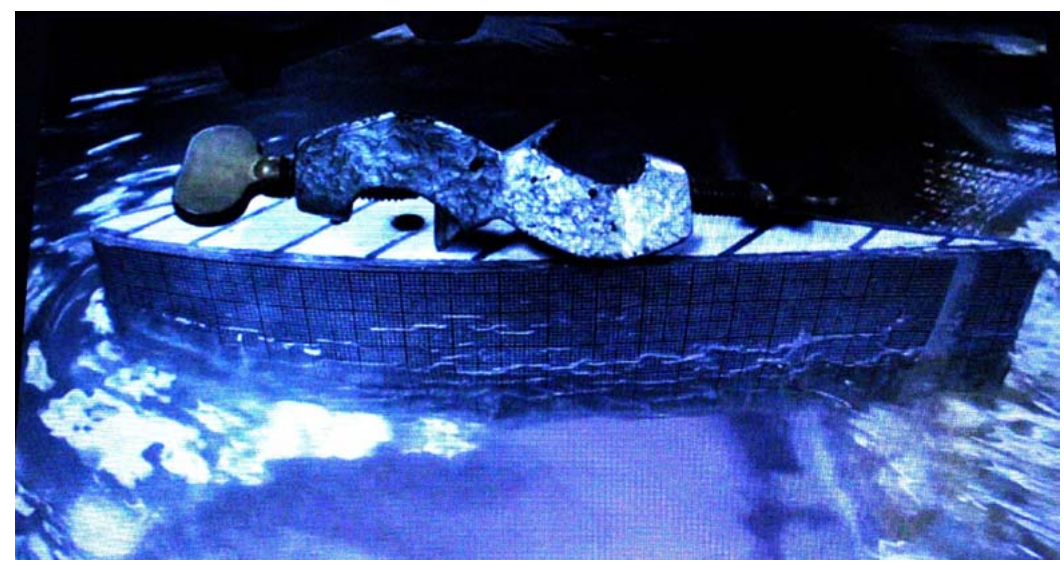

Figure 13. Effects of roughness increase showed on the water table
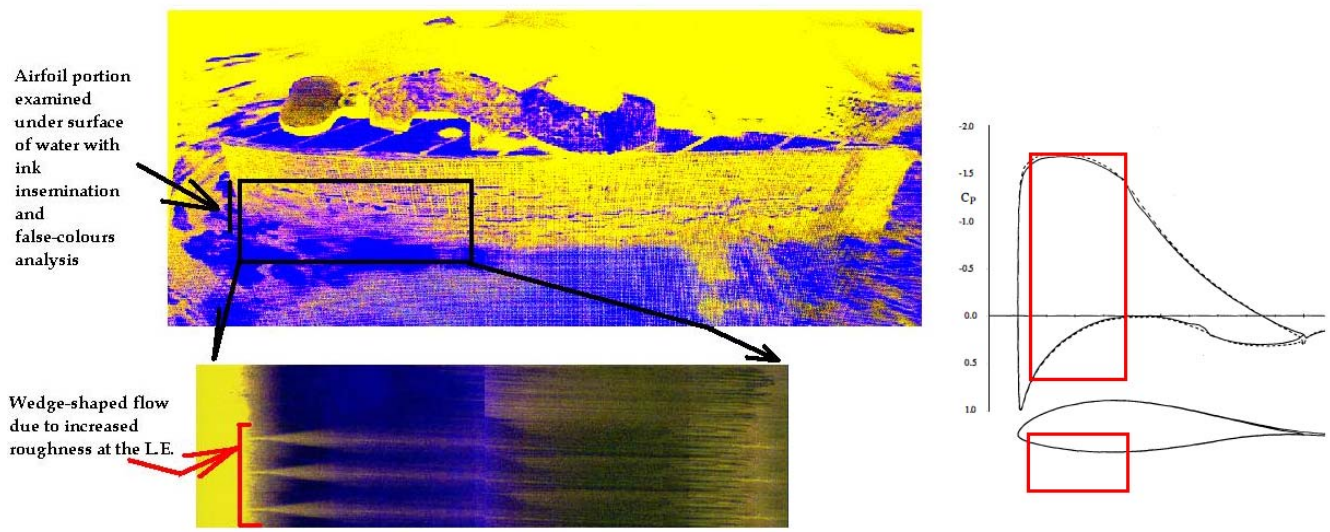

As shown in Fig. 13 (FFA-W1-182), the roughness increase at the L.E. produces a wedge-shaped flow detected by ink insemination and false colours analysis. This flow produces a sharp drop in pressure coefficient, resulting in a lower maximum lift coefficient, but the particular shape of the camber line and the lower surface produces a lift recovery and so, as shown in Fig. 19, there is a "soft stall" after maximum value or a T.E. (Trailing edge) stall.

These results and those exposed in Fig. 15 are in good agreement with results exposed in [11b]. The corresponding tests carried out on the wind tunnel and on the water table were inspired by [11b].

NACA 23018 airfoil shows the larger sensitiveness to roughness increase at the L.E. and the ice accretion seems to destroy the "lift structure", resulting in sharp stall with the lower lift coefficient value (0.9). 
Figure 14. $\mathrm{C}_{\mathrm{p}}$ for NACA 23018 wing section

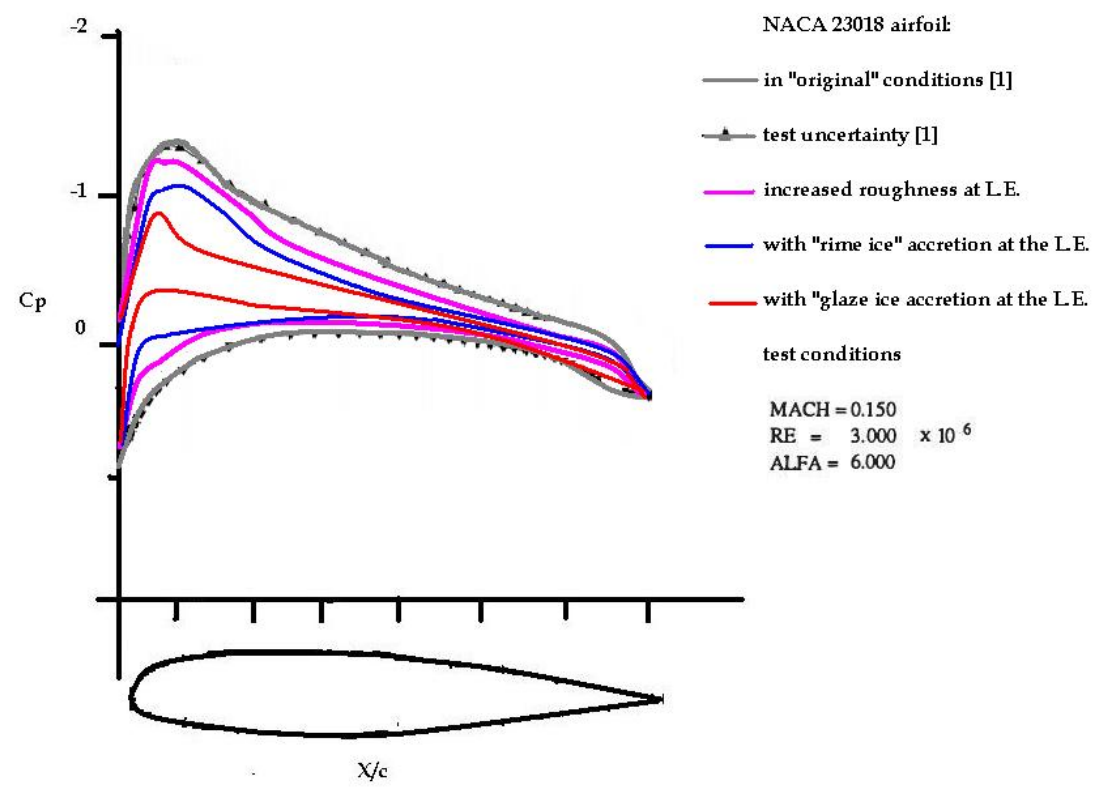

NREL S809 wing section seems to show a more moderate sensitivity to roughness increase, while the ice accretion modifies the shape and the slope of lift curve.

The ice accretion seems to produce a remarkable modification of zero lift direction and a sharp drop in maximum lift coefficient.

Figure 15. $C_{p}$ for NREL $S 809$ airfoil

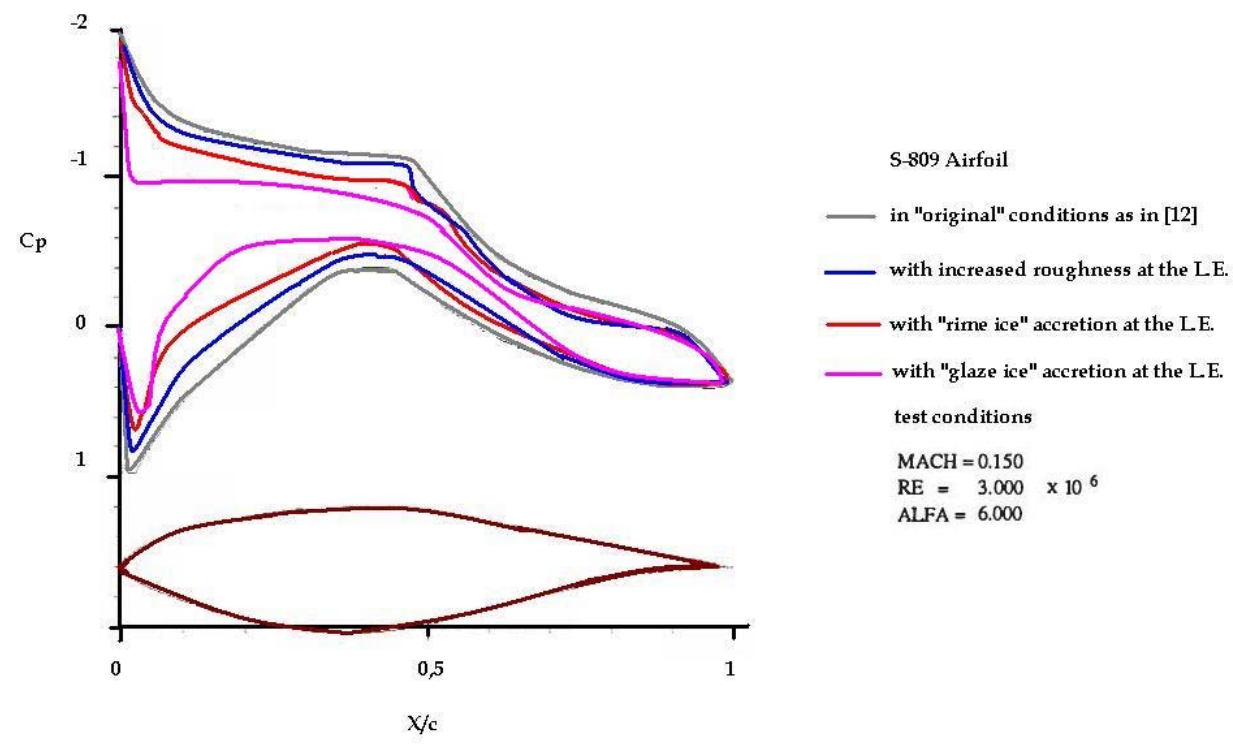


Figure 16. $\mathrm{C}_{\mathrm{p}}$ for FFA-W1-182 profile

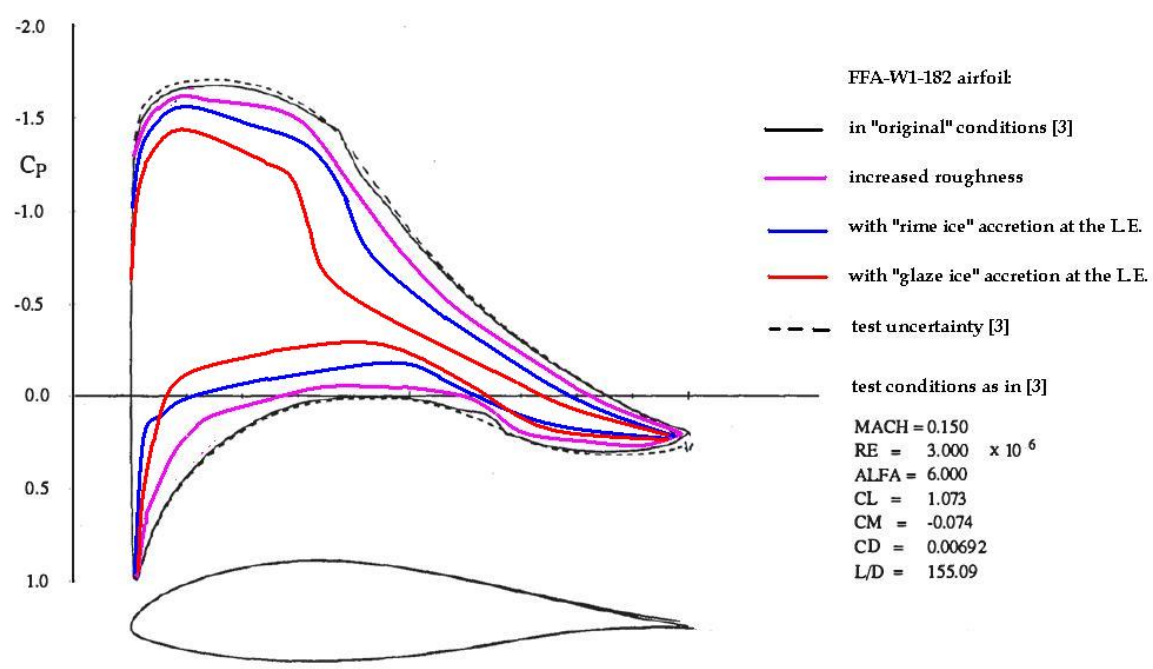

The FFA-W1-182 wing section shows the best behaviour due to its particular shape of the camber line and the lower surface and the consequent boudary layer control (see [2] and [3]).

Also when a glaze ice accretion occurs at the L.E., its $\mathrm{C}_{\mathrm{l}-\max }$ remains higher than other ones: $1.25 \mathrm{vs}$. 0.92 for S809 and 0.89 for NACA 23018.

It shows also the lower shift in zero lift direction, only $1^{\circ}$ (from $-3^{\circ}$ to $-2^{\circ}$ ) vs. $4^{\circ}$ for NACA 23018 and $2^{\circ}$ for $\mathrm{S} 809$.

The FFA-W1-182 slope of lift curve remains the same while the others are changed in remarkable way.

In the end, FFA-W1-182 wing section shows a significant resistence to roughness increase maintaining a generally good performance with a roughness increase as well as it is as in Fig. 3.

While the wind tunnel has been very useful in analysing the $C_{p}$ of wing sections, the water table allowed to reproduce in the analogy the real operative conditions in a way very few expensive. The Analogy, as assessed by [8] and by using the apparatus according to [9] produce very good results. The global error on wind tunnel was about $1-2 \%$, while on the water table it was about $3.42 \%$ (due to the difference showed in Fig. 9). 
Figure 17. $C_{1}$ FOR NACA 23018 airfoil

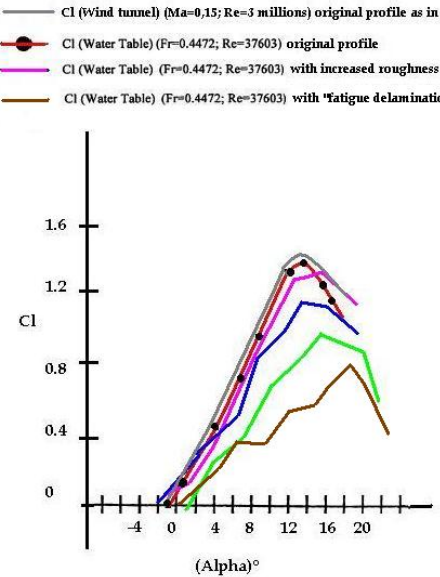
NACA 23018 Airfoil
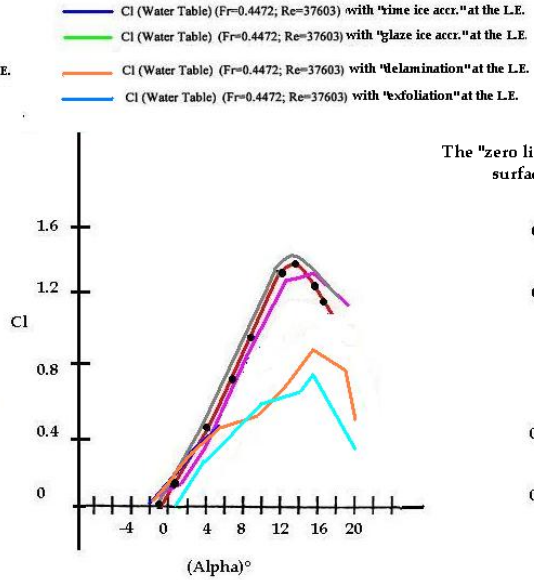

The "zero lift direction" variation due to airfoil surface and geometry variations
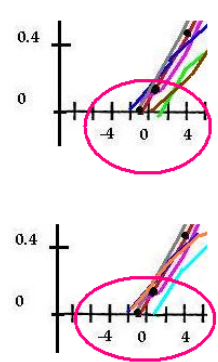

Figure 18. $C_{1}$ for NREL S809 airfoil NREL - $\$ 809$ Airfoil
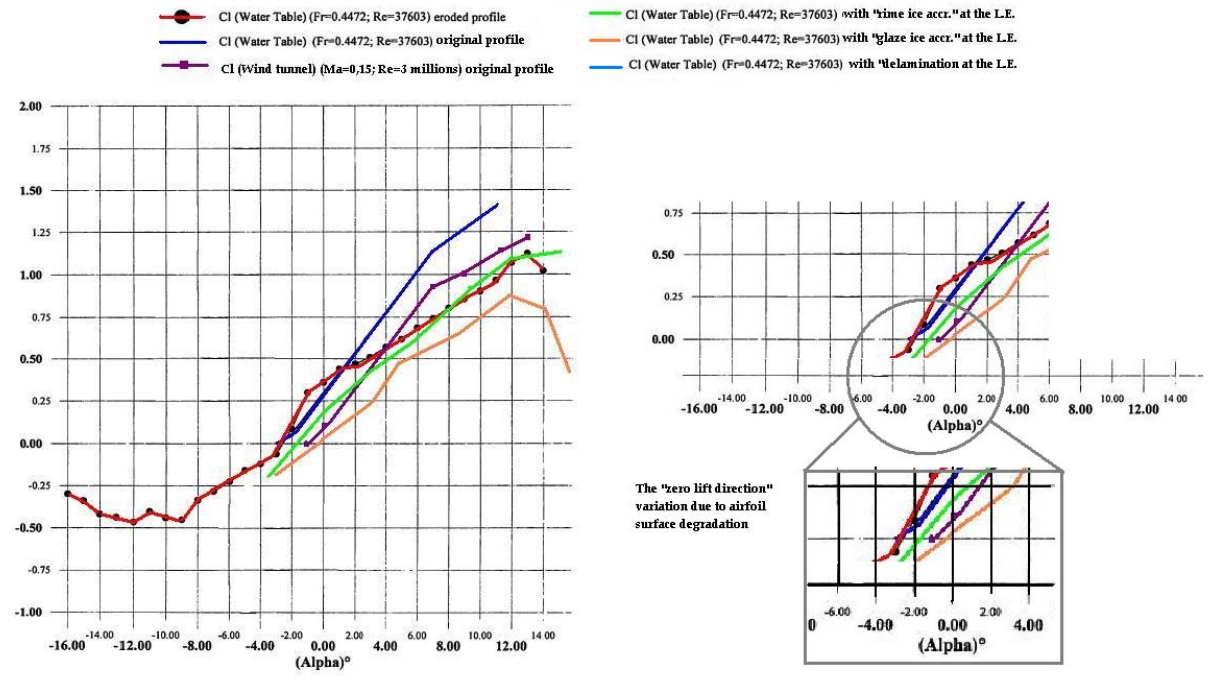
Figure 19. $\mathrm{C}_{1}$ for FFA-W1-182 wing section

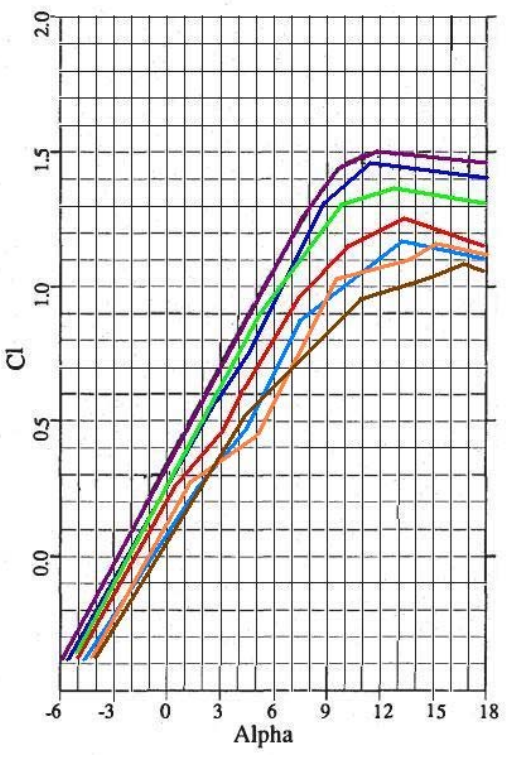

FFA-W1-182 airfoil

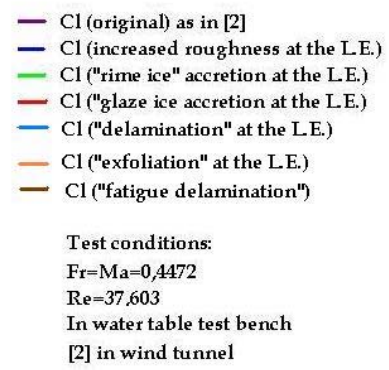

The "zero lift direction variation
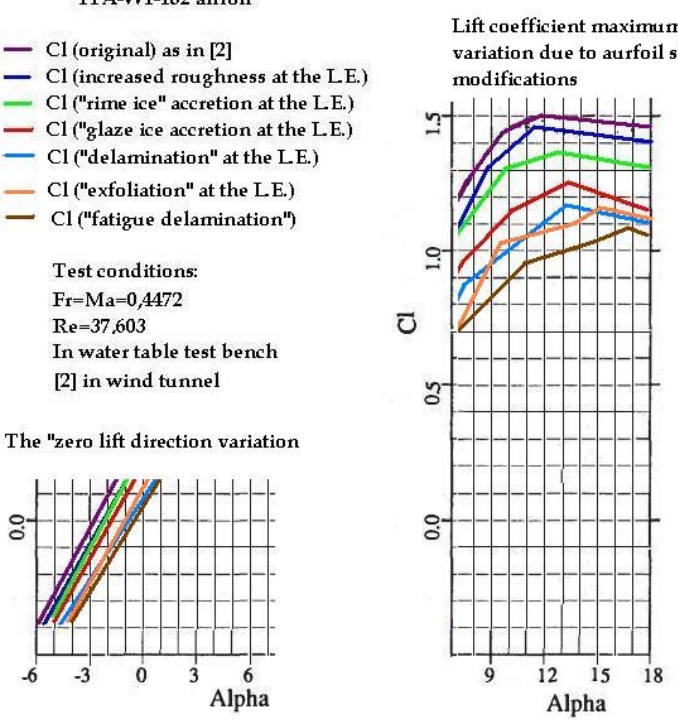

Figure 20. $C_{p}$ abacus for the preceding figures

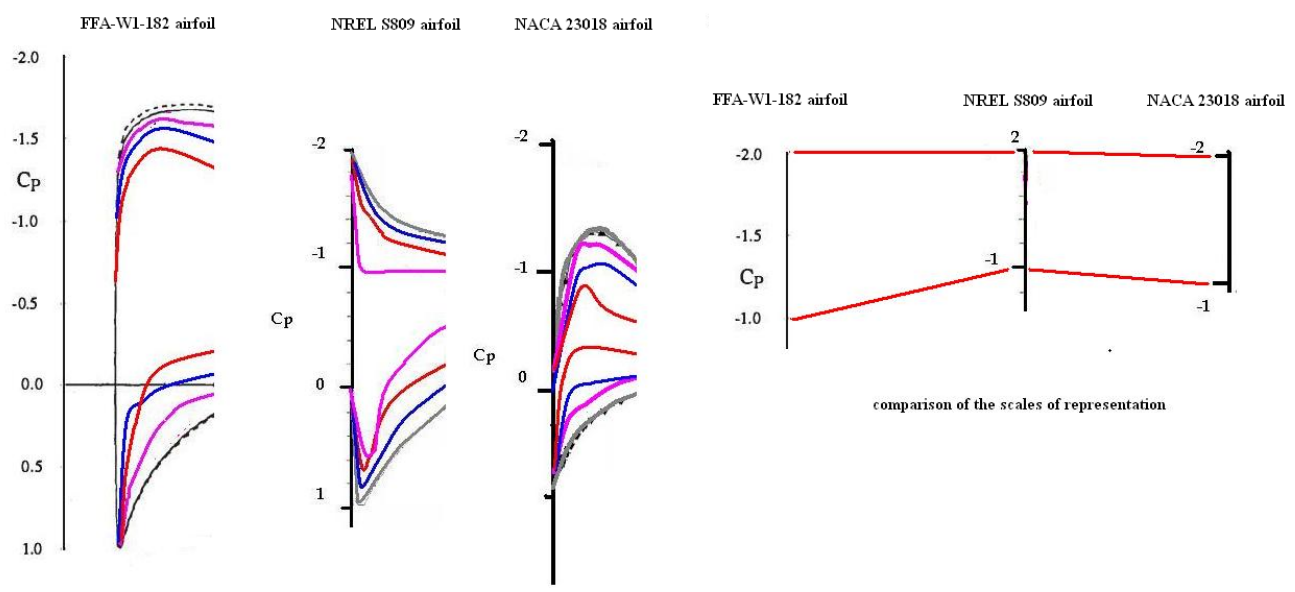

Figure 21. $C_{1}$ abacus for the preceding figures 

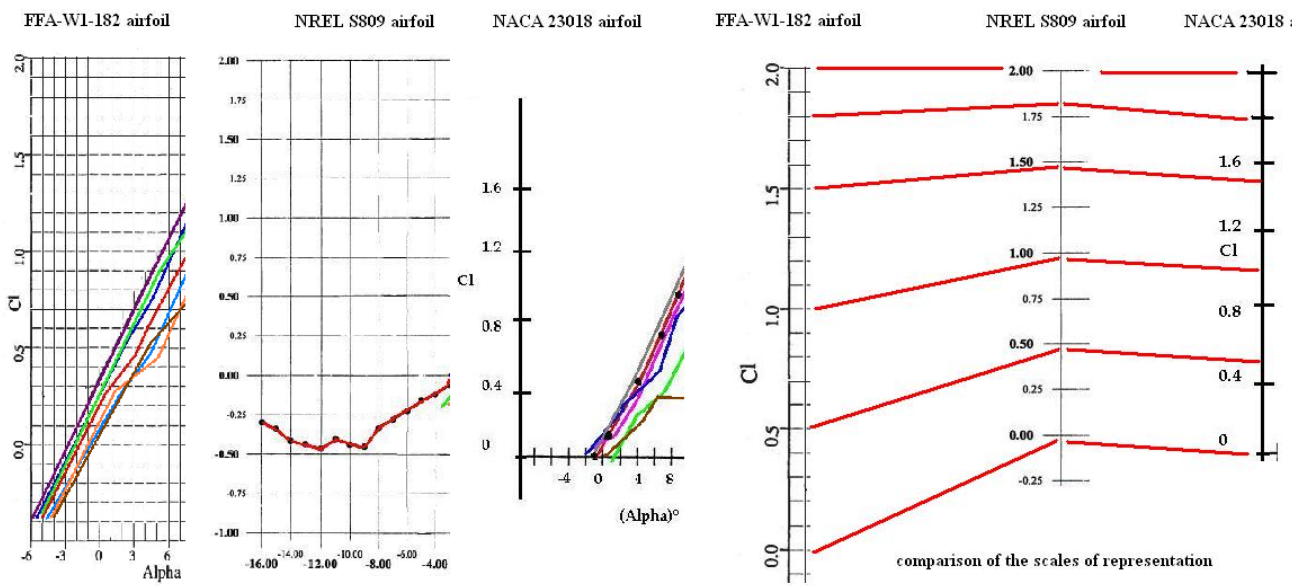

\section{Conclusive remarks}

As above exposed, the conditions of roughness increase and ice accretion on HAWT's rotor blades have been analysed and the results showed the envisaged and detected remarkable aerodynamical performance decay. Every tested airfoil is characterised about by the same or similar thickness ratio.

The ice accretion seems to have a large effect on $\mathrm{C}_{\operatorname{lmax}}$ value, greater than camber line one's. On the other hand, the surface roughness increase has large effect on wing characteristics and ice accretion is a colossal roughness increase at the L.E. as well.

The angle of zero lift of wing sections is largely determined by the airfoil camber, nevertheless some ice accretion shapes modifies the original value in a remarkable way and also a distributed roughness increase seems to have a similar although slighter effect. The glaze ice accretion shape seems to have the major effect while the rime ice one seems to affect more the slope of lift curve, but the glaze ice accretion shape transforms this slope in a remarkable way.

Traditional aerodynamic profiles, as NACA 23018, have showed very high sensitivity to the ice accretion or augmented roughness, while new airfoils as FFA-W1-182 may be very useful in maintaining higher aerodynamical performance.

FFA-W1-182 has shown the better behaviour under roughness increase conditions and ice accretion ones. In moutainous and harsch climate sites we can expect particularly the effects due to ice accretion, while erosion and fouling, resulting in a roughness increase, may occur in offshore sites, due to salt and moisture actions. 
In every condition, the behaviour of FFA-W1-182 airfoil seems to be the better, with a reduced decay in $\mathrm{C}_{\text {lmax }}$, and maintaining the slope and the overall shape of the lift curve, with the T.E. stall characteristic.

The combined use of wind tunnel and the water table test bench has been very useful because of the first operates in full similarity while the second operates in analogy with important facilitations as the test value of $\mathrm{Ma}=\mathrm{Fr}$ higher $(0.4472)$ than wind tunnel one $(\mathrm{Ma}=0.15)$. The second conditions are more similar to wind turbines blades operative running conditions.

The results have been compared with literature data as in [11], [5], [7] and [13], showing a good agreement. The comparison have suggested further experimental analysis that will be carried out as soon as possible.

\section{References}

[1] ABBOTT, I. H., von DOENHOFF, A. E. (1959): "Theory of Wing Sections - including a Summary of Airfoil data", New York, Dover Publications Inc., pp.693;

[2] BJÒRCK, A. (1989): "Airfoil Design for Variable Rpm Horizontal Axis Wind Turbine"', in FFAReport-1989, pp. 100;

[3] BJÒRCK, A. (1990): "Coordinates and Calculations for the FFA - W1 - XXX, FFA- W2-XXX and FFA - W3 -XXXSeries of Airfoils for Horizontal Axis Wind Turbines", FFA TN 1990-15, FFA-Flygtekniska Fòrsòksanstalten, Stockholm, pp. 148;

[4] DE PRATTI, G. M. et Al. (1997): "Performance Analysis of New Wind Turbine Biade Profiles", in Wind Engineering, vol. 21 n 5/1997, pp. 295-306;

[4b] DE PRATTI, G.M. et Al. (2003) : Performance Decay Analysis of New Rotor Blade Profiles for Wind Turbines Operating in Offshore Environments, in Wind Engineering, Sept. 2003, Vol. 27, $\mathrm{n}^{\circ}$ 5, pp. 371-379;

[4c] DE PRATTI, G. M. et Al. (2003): "Ice accretion on new blade profiles and performance decay analysis of hawts operating in high latitude offshore sites", in Proc. of The OWEMES 2003, pp. 7;

[5] EHRMANN, R. S. (2013): "Realistic Leading-Edge Roughness Effects on Airfoil Performance, in SAND2013-4412C, pp. 18;

[6] HILL, D.C., and GARRAD, A.D. (1989): "Design of Aerofoils for Wind Turbine Use", in PALZ, W. (ed.), 1989 EWEC-European Community Wind Energy Conf., Proc. of an Int. Conf. Glasgow, H.S. Stephens \& Associates, Bedford, pp. 73-77;

[7] MUNAKATA, H. et al. (1990): "Wind Tunnel Test of Rotor Aerodynamics with Various Surface

Roughness", in Proceedings of the European Community Wind Energy Conference 10-14 september 1990, Madrid, Spain, pp. 363-367;

[8] ORLIN, J. W. et al. (1947): "Application of the Analogy between Water Flow with a Free Surface and Two-Dimensional Compressible Gas Flow", NACA Report n 875, pp. 18;

[9] SHAPIRO, A. H. (1949): "An Appraisal of the Hydraulic Analogue to Gas Dynamics", in Meteor Unclassified Report MIT Library n 001-6-1949, Cambridge, MIT; 
[10] SPERA, D. A. (ed.) (1994): "Wind Turbine Technology - Fundamental Concepts of Wind Turbine Engineering -, New York, ASME PRESS, pp. 638;

[11] TANGLER, J. et Al.(1990): "Atmospheric Performance of the Special-Purpose SERI ThinAirfoil Family: Final Results" In PALZ, W.(ed.), 1990 European Community Wind Energy Conference, 10-14 September 1990 Madrid Spain, Proceedings, pp. 198-202;

[11b] TANGLER, J. et Al. (1997): "Design and Experimental Results for the S809Airfoil", in NRELISR-440-6918 -UC Category: 1213 - DE97000206, Golden (Colorado), January 1997, pp. 103 ;

[12] TIMMER, W. A. and van ROOY, R.P.J.O.M. (1992): "Thick airfoils far HAWTs", in Journal of Wind Engineering and Industrial Aerodynamics, v. 39, pp. 151-160;

[13] WANG, Y. et Al. (2016): "Effects of Leading Edge Defect on the Aerodynamic and Flow Characteristics of an S809 Airfoil”, in PLOS ONE, DOI:10.1371/journal.pone.0163443 September 22, 2016, pp. 17. 